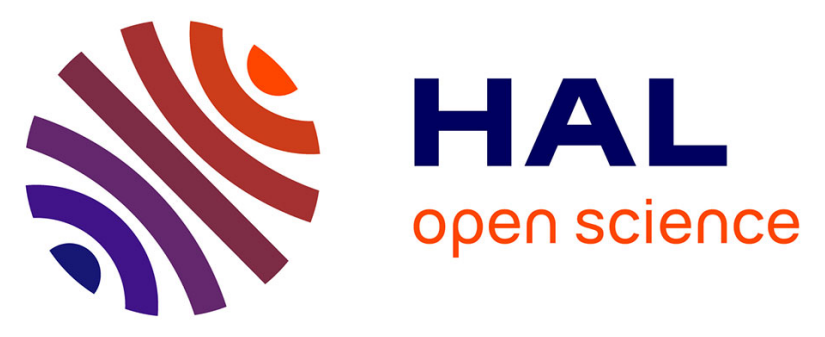

\title{
Scanning Electrochemical Microscopy of Belousov-Zhabotinsky Reaction: How Confined Oscillations Reveal Short Lived Radicals and Auto-Catalytic Species
}

T. Jane Stockmann, Jean-Marc Noël, Sandra Ristori, Catherine Combellas, Ali Abou-Hassan, Federico Rossi, Frédéric Kanoufi

\section{To cite this version:}

T. Jane Stockmann, Jean-Marc Noël, Sandra Ristori, Catherine Combellas, Ali Abou-Hassan, et al.. Scanning Electrochemical Microscopy of Belousov-Zhabotinsky Reaction: How Confined Oscillations Reveal Short Lived Radicals and Auto-Catalytic Species. Analytical Chemistry, 2015, 87 (19), pp.96219630. 10.1021/acs.analchem.5b01238 . hal-01480761

\section{HAL Id: hal-01480761 https://hal.science/hal-01480761}

Submitted on 3 Apr 2017

HAL is a multi-disciplinary open access archive for the deposit and dissemination of scientific research documents, whether they are published or not. The documents may come from teaching and research institutions in France or abroad, or from public or private research centers.
L'archive ouverte pluridisciplinaire HAL, est destinée au dépôt et à la diffusion de documents scientifiques de niveau recherche, publiés ou non, émanant des établissements d'enseignement et de recherche français ou étrangers, des laboratoires publics ou privés. 


\title{
Scanning Electrochemical Microscopy of Belousov- Zhabotinsky Reaction: How Confined Oscillations Reveal Short Lived Radicals and Auto-Catalytic Species.
}

\author{
T. JaneStockmann, ${ }^{\mathrm{a}}$ Jean-Marc Noël, ${ }^{\mathrm{a}}$ Sandra Ristori, ${ }^{\mathrm{b}}$ Catherine Combellas, ${ }^{\mathrm{a}}$ Ali Abou-Hassan, ${ }^{\mathrm{c}}$ Federico Rossi, ${ }^{\mathrm{d}}$ and \\ Frédéric Kanoufi ${ }^{\mathrm{a}, \uparrow}$ \\ ${ }^{a}$ Sorbonne Paris Cité, Paris Diderot University, Interfaces, Traitements, Organisation et Dynamique des Systèmes, CNRS- \\ UMR 7086, 15 rue J.A. Baif, 75013 Paris, France. \\ ${ }^{\mathrm{b}}$ Department of Earth Sciences \& CSGI, Via della Lastruccia 3, 50019 Sesto Fiorentino, Firenze, Italy \\ ${ }^{c}$ Université Pierre et Marie Curie, Laboratoire Physico-chimie des Electrolytes et Nanosystèmes Interfaciaux, CNRS-UMR \\ 8234, 4 place Jussieu, 75005 Paris, France. \\ ${ }^{\mathrm{d}}$ Department of Chemistry and Biology, University of Salerno, Via Giovanni Paolo II, 132, 84084, Fisciano (SA), Italy
}

\begin{abstract}
The effect of confinement on the Belousov-Zhabotinksy (BZ) oscillating reaction, (employing ferroin as a catalyst and malonic acid as the organic substrate) has been investigated using scanning electrochemical microscopy (SECM) toward different insulating surfaces such as glass, silanized glass, or PTFE. An unexpected increase in the amplitude of the BZ reaction at a tipsubstrate distance of $\sim 12-15 \mu \mathrm{m}$ was observed. By simulating different reaction mechanisms, from simple $\mathrm{EC}^{\prime}$ catalysis, to more sophisticated Oregonator or full scheme, it is shown that such behavior reveals the intervention of redox catalysis processes and particularly the short lived highly reactive radical intermediate $\mathrm{BrO}_{2}{ }^{\circ}$ indirectly detected at the $\mu \mathrm{M}$ concentration. The re-inspection of the EC' mechanism shows how the intervention of the homogeneous catalysis route is easily confirmed and kinetically characterized from SECM towards an insulating substrate, with promising potentiality in many systems. More specifically to the complex chemical case of BZ reactions, the mechanism is understood from the envelope curves of the oscillations, which are assessed in the absence of the oscillation (absence of organic substrate).
\end{abstract}

\section{1. - INTRODUCTION}

The synergism of complex, out-of-equilibrium chemical reactions responsible for homogeneous redox catalysis, ${ }^{1,2}$ rely on a redox catalyst couple $(\mathbf{O x} / \mathbf{R e d})$ to act as an electron shuttle and transfer electrons to an electroactive species (A for example in (2) and $\mathbf{B}$ its reduced form):

$$
\begin{aligned}
& \mathrm{Ox}+e^{-} \rightarrow \mathrm{Red} \\
& \mathrm{Red}+\mathrm{A} \rightarrow \mathrm{B}+\mathrm{Ox}
\end{aligned}
$$

The success of such a EC' catalytic reaction scheme comes from the feedback due to the regeneration of $\mathbf{O x}$ and also because the electron shuttle drives the reduction of $\mathbf{A}$ at a potential more positive than its direct reduction. This mechanism has been popularized in many molecular and biomolecular systems, from: organic electrochemistry ${ }^{5}$ or molecular electrocatalysis, where it is involved in proton coupled electron transfer processes, ${ }^{6}$ important for molecular solutions to energy conversion; or in many homogenenous biomolecular processes ${ }^{7}$ to electrochemically-driven cross-coupling reactions, ${ }^{8,9}$ in atom-transfer radical polymerization, ${ }^{10}$ or in multireaction chemical processes as Electrochemiluminescent (ECL) ${ }^{11-13}$ and oscillating reactions.

These are complex, coupled multi-reaction systems, operating far from equilibrium, with positive and negative feedback loops that cause the reaction coordinate to transition between different concentration states. ${ }^{14,15}$ These reactions have been incorporated into ionic liquids, ${ }^{16,17}$ along with polymers and gels, ${ }^{18-21}$ where they have generated unassisted or autonomous movement through swelling/deswelling events. The most famous example, the Belousov-Zhabotinsky (BZ) reaction, involves the oxidation of an organic substrate, typically malonic acid, by bromate in the presence of an excess of strong acid. $^{14,15,22}$ The overall shift in concentration is monitored through a redox catalyst such as cerium IV,,$^{22,23}$ a variety of ruthenium complexes, ${ }^{21,24,25}$ ferroin, ${ }^{18,26,27}$ that are conveniently redox and/or photo-active. The BZ reaction has been widely studied in many experimental configurations ${ }^{22,28}$ including in confined environment by incorporating it inside synthetic vesicles for example. Interestingly, such system shows analogies to biological systems, particularly mimicking intercellular communication. $^{26,29,30}$ Thus, evaluating the kinetics/thermodynamics of such reactions in a confined environment is a unique challenge for microfluidics. ${ }^{14,26,31-34}$ Scanning electrochemical microscopy (SECM), with its recognized high mechanistic sensitivity, is proposed here as an interesting alternative.

SECM has been used extensively for interrogating the reactivity of chemical species in solution, at a substrate, ${ }^{3,4,35-43}$ as well as for characterizing short-lived radical species. ${ }^{37,39-}$ ${ }^{41,43}$ Therefore, from both geometric and mechanistic aspects, SECM is ideal to interrogate oscillating chemical reactions in confined conditions. SECM is also employed to differentiate between spatiotemporal effects and purely chemical ones, through quantification of the kinetics/dynamics of confine- 
ment -i.e. between the tip and substrate. This also provides a convenient analog for the study of confinement vis-à-vis inside vesicles. An unexpected confinement effect was demonstrated and characterized using simulations of increasing complexity. Starting from the simplest $\mathrm{EC}^{\prime}$ mechanism reinspected here for simpler SECM configuration (negative feedback) than the generation-collection one, ${ }^{3,4}$ SECM is applied to comprehend complex catalytic systems, such as the BZ reaction. The detailed model of the $\mathrm{BZ}$ reaction reproduces the experimental observation, highlighting the intervention of short-lived radical intermediates.

\section{EXPERIMENTAL}

All reagents were purchased commercially and used without purification (complete list provided in the Supporting Information, SI). Stock aqueous solutions of ferroin sulphate salt ( $\mathrm{Fe}(\text { phen })_{3} \mathrm{SO}_{4}$ ) were prepared by mixing 1,10 -phenanthroline (phen) and iron (II) sulfate in a molar ratio of 3:1. Aqueous solutions were prepared using Milli-Q ultrapure purified water $(>18.2 \mathrm{M} \Omega \cdot \mathrm{cm})$.

Typical BZ reaction solutions are made from $2 \mathrm{mM}$ ferroin, $1 \mathrm{M} \mathrm{H}_{2} \mathrm{SO}_{4}, 120 \mathrm{mM}$ malonic acid and $180 \mathrm{mM} \mathrm{NaBrO}_{3}$.

Microelectrodes were prepared in a procedure described elsewhere $^{44}$ and detailed in the SI. Approach curves were measured by biasing the microelectrode on the ferriin to ferroin reduction plateau $\left(\mathrm{Fe}(\mathrm{phen})_{3}{ }^{3+}+\mathrm{e}^{-} \rightarrow \mathrm{Fe}(\mathrm{phen})_{3}{ }^{2+}\right)$ $\mathrm{E}_{\mathrm{T}}=0.1 \mathrm{~V}$ versus a $\mathrm{Pt}$ counter/quasi-reference as determined through cyclic voltammetry (CV in Figure S5). Approach curves in the feedback mode were performed at a rate of $1 \mu \mathrm{m} \cdot \mathrm{s}^{-1}$ whereas in transient mode, the tip-substrate distance was changed periodically every $5 \mu \mathrm{m}$ while an average of $\sim 10$ oscillations was recorded for each distance.

A Drop Shape Analyzer (DSA30, Krüss GmbH, Villebon sur Yvette, France) was employed for water contact angle measurements of silanized Glass (preparation described in SI).

\section{SIMULATIONS}

Details of the finite element simulations by COMSOL are given in the SI. Briefly, different catalytic schemes, starting from the simple EC' case, were considered in the SECM configuration with an insulating substrate (unless otherwise stated). It consists in solving the time-dependent diffusion equations for the different species involved with consideration of their net generation from chemical reactions in solution. Transformation of ferriin and ferroin at the microelectrode surface provides the tip current. Approach curves are simulated as steady-state or long-time $(>100$ s) tip current values evaluated at different tip-substrate distances. The time evolution of the tip current simulates oscillations.

\section{RESULTS AND DISCUSSION}

\subsection{EC' Mechanism by SECM Approach Curves}

Simulation of the EC' scheme in the SECM configuration with a conducting substrate can be found elsewhere, ${ }^{3,4}$ along with strategies to extract the kinetics of the catalytic reaction from feedback collection between the tip and a conducting substrate. Since insulating substrates are intrinsically easier to produce than perfectly conducting ones, a simpler strategy for kinetic analysis of EC'processes relies on the SECM probe approach curve towards an insulating substrate in the presence of the appropriate $\mathrm{EC}^{\prime}$ counterparts - namely Ox and A. The tip, of radius $a$, is held at large tip-substrate distances (d > 10a), and biased at a potential negative enough to produce Red (eq. 1) under mass-transfer limit. The steady-state current $\left(i_{\text {inf }}\right)$ is limited by the diffusion of $\mathrm{Ox} /$ Red and $\mathrm{a}^{3,38}$ the catalytic regeneration of Ox by (2). The direct estimate of the catalytic reaction rate $k_{\text {homo }}$ of reaction (2) may then be obtained from comparison of $i_{\text {inf }}$ in the absence and presence of $\mathbf{A}$, as illustrated through a plot of $i_{\text {inf }}$ versus $k_{\text {homo }}$ in Figure S1.

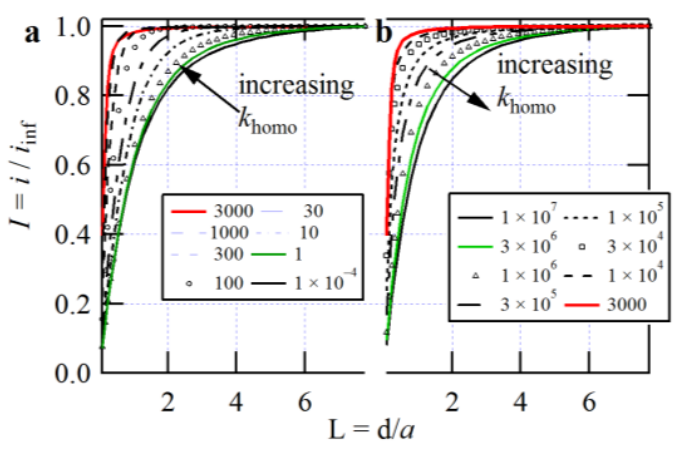

Figure 1: Simulated SECM approach curves using the $\mathrm{EC}^{\prime}$ mechanism (eqs. 1 and 2) with $k_{\text {homo }}$ from $10^{-4}$ to $3000 \mathrm{M}^{-1} \cdot \mathrm{s}^{-1}$ [a] and 3000 to $10^{7} \mathrm{M}^{-1} \cdot \mathrm{s}^{-1}[\mathbf{b}] ; 25 \mu \mathrm{m}$ diameter tip with $\mathrm{Rg}=5$.

The simulated approach curves for EC' schemes are provided in Figure 1 for different catalytic rates, $k_{\text {homo, }}$ under the condition such that $\mathbf{A}$ is in excess. Normalization of the recorded tip current, $i_{\mathrm{T}}$, by its value at large distance, $i_{\text {inf }}$, facilitates comparison, even though it is recalled that $i_{\text {inf }}$ increases with $k_{\text {homo }}$.

Typically in the absence of A, or for low catalytic regeneration compared to Ox diffusion $\left(k_{\text {homo }}[\mathbf{A}] a^{2} / D_{\text {Ox/Red }}<0.01\right)$, as the tip approaches the insulating substrate, diffusion of $\mathrm{Ox}$ to the electrode surface is hindered, resulting in a negative feedback response (black line in Figure 1a). When increasing the catalytic rate, $k_{\text {homo }}$, the homogeneous catalytic reaction generates a concentration change at the tip as the catalyst consumes Red to regenerate $\mathrm{Ox}$ in a reaction layer that decreases as $k_{\text {homo }}$ increases. This reaction layer may be smaller than the dimensions of the tip and its perturbation by the substrate (decrease of $\left.i / i_{\text {inf }}\right)$ is observed for shorter tip-substrate separation distances - i.e. shorter values of $\mathrm{L}=\mathrm{d} / a-$ than for the standard negative feedback regime. The increase of $k_{\text {homo }}$ then yields a compaction of the approach curve towards the substrate (Figure 1a). Upon further increase of $k_{\text {homo, }}$ the approach curve then departs from the substrate and tends again towards the standard negative feedback curve (Figure 1b). In this regime of $k_{\text {homo }}$ values, the catalytic reaction is so fast that the process is driven by the diffusion of $\mathbf{A}$ and no longer by Ox/Red, while the negative feedback refers to diffusion hindrance of $\mathbf{A}$. This is further exemplified through a plot of $I_{\min }=i_{\min } / i_{\text {inf }}$ versus $k_{\text {homo }}$, in Figure $\mathrm{S} 1 \mathrm{~b}$, such that $I_{\min }$ taken at $\mathrm{L}=0$ undergoes an increase as $k_{\text {homo }}$ approaches $3000 \mathrm{M}^{-1} \cdot \mathrm{s}^{-1}$ and subsequently decreases. Interestingly, from a mechanistic point of view, a precise kinetic analysis of $k_{\text {homo }}$ can be obtained by SECM approach curves towards an insulating substrate.

The full illustration of such mechanistic approach is further demonstrated in the complex chemical situation encountered in BZ oscillating reactions. 


\subsection{Approach Curves in BZ Solution with Malonic Acid.}

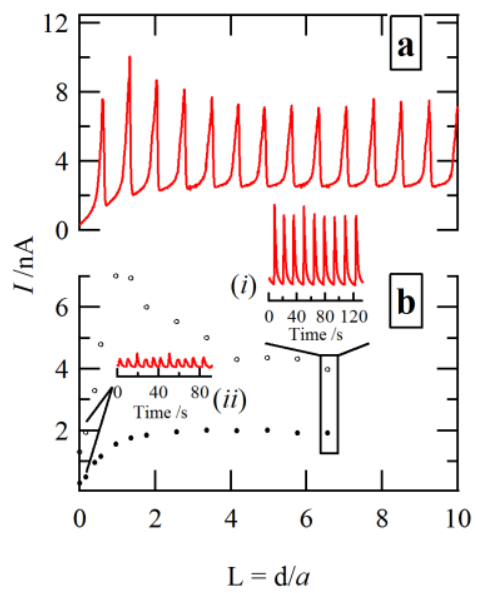

Figure 2: [a] Probe approach curve using a $25 \mu \mathrm{m}$ diameter $\mathrm{Pt}$ disk tip $\left(\mathrm{R}_{\mathrm{g}}=5\right)$ towards a glass substrate with a $\mathrm{BZ}$ aqueous solution composed of $180 \mathrm{mM} \mathrm{NaBrO}, 120 \mathrm{mM}$ malonic acid, $1 \mathrm{M} \mathrm{H}_{2} \mathrm{SO}_{4}$, and $2 \mathrm{mM}$ ferroin. [b] Probe approach curves obtained in transient mode from the maximum (०) and minimum (•) oscillation current. Insets correspond to $\sim 10$ oscillations recorded at the distance indicated.

The kinetics of the BZ reaction were examined experimentally using SECM probe approach curves as described in the experimental section and the SI. Briefly from a BZ solution containing $\mathrm{Fe}$ (phen $)_{3}{ }^{3+}$, a SECM tip generating $\mathrm{Fe}(\text { phen })_{3}{ }^{2+}$ is approached to a glass substrate while the BZ reaction cycle catalytically regenerates $\mathrm{Fe}(\text { phen })_{3}{ }^{3+}$.

At $\mathrm{L}>10, i_{\text {inf }}$ oscillates with time, undergoing a sharp increase in amplitude that is followed by a rapid decay period, which subsequently repeats with a period of $\sim 12-15 \mathrm{~s}$, in excellent agreement with our previous results ${ }^{26}$ and with other literature data ${ }^{14,18,23}$ for similar BZ systems. The tip was then approached slowly to a glass insulating substrate while recording the tip current, $i_{\mathrm{T}}$, reported as the red trace in Figure 2a. A highly reproducible increase in the amplitude of the oscillation was observed when the tip was $12-15 \mu \mathrm{m}$ from the surface. More quantitative experiments were performed in the transient mode by periodically changing the tip-substrate distance and recording an average of $\sim 10$ oscillations.

This is exemplified using two transient curves (insets in Figure 2b) at tip-substrate distances of 90 and $5 \mu \mathrm{m}$ for $(i)$ and (ii), respectively. For each distance, the mean current oscillation minimum and maximum tip current were calculated (Figure $2 \mathrm{~b}$ ). It can be observed that while the tip-substrate distance does not significantly affect the oscillation frequency, it has a considerable effect on its amplitude. When the tip approaches the substrate, i) the amplitude increases by up to a factor of 2 before sharply decreasing by a factor of 20 when going into contact with the substrate (Figure $2 a$ ) and, ii) only the maximum current value has increased in a partial positive feedback, whereas the baseline current is essentially decreasing in a behaviour analogous to the negative feedback.

To understand the origin of this unexpected partial positive feedback, one may recall that oscillations in such chemical systems are owing to what is generally held to be 2 or 3 proc- esses $->20$ individual reactions ${ }^{28,45}$ - as recently reviewed. ${ }^{14,15}$ To eliminate the chemical nature of the substrate as a possible factor responsible for the partial positive feedback, similar transient analysis of the BZ oscillations was performed at different insulating substrates, including silanized glass using $\left(\mathrm{C}_{12} \mathrm{H}_{25}\right) \mathrm{Si}\left(\mathrm{CH}_{3}\right)_{2} \mathrm{Cl}$ and $\left(\mathrm{CH}_{3} \mathrm{CH}_{2} \mathrm{O}\right)_{3} \mathrm{Si}\left(\left(\mathrm{CH}_{2}\right)_{2} \mathrm{C}_{8} \mathrm{~F}_{17}\right)-$ and PTFE (details in the SI). The same increase in the oscillation amplitude was observed, as presented in Figure S2, for all these insulating substrates, with a maximum amplitude at $\sim 12$ $15 \mu \mathrm{m}$ tip-substrate distance, showing no significant effect of the substrate. Furthermore, nearly constant water contact angles were measured before and after each experiment at silanized glass (Table S1); therefore, it can be concluded that no appreciable chemical process occurred at the surface that may be responsible for the apparent partial positive feedback observed. It also indicates that the silanized layers have not been significantly etched by the strongly acidic and oxidative conditions provided by the $\mathrm{BrO}_{3}{ }^{-}$solution. If a complete understanding of the distance-effect phenomenon is ruled by the chemistry of the system, it is quite unusual, since such a positive feedback response has never been observed in chemical situations without involving interfacial charge transfer.

\subsection{Oregonator-SECM Coupled Model}

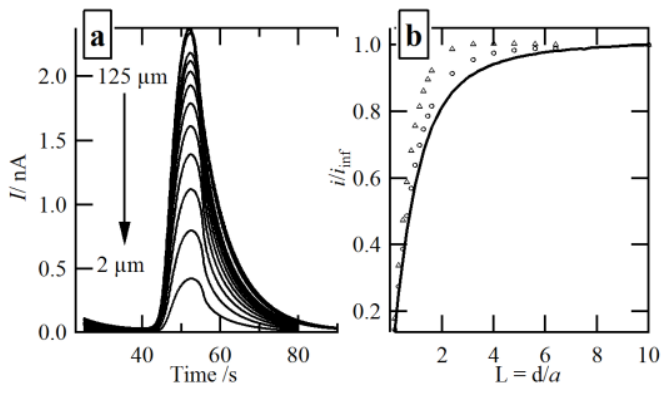

Figure 3. [a]Overlay of selected, simulated chronoamperograms at a SECM tip $(a=12.5 \mu \mathrm{m}, \mathrm{Rg}=5)$; tip-substrate distances from 125 to $2 \mu \mathrm{m}$. The homogeneous phase incorporated a 6-reaction kinetic Oregonator model. [b] Plot of the normalized maximum $(\triangle)$ and minimum $(\circ)$ current amplitudes of the simulated transient curves in $[\mathbf{a}]$ versus negative feedback $(-)$.

Classically, BZ reactions are kinetically described using the 'Oregonator', as developed by Field, Körös, and Noyes. ${ }^{45,46}$ This model seeks to condense the large array of reactions into a system reliant on two dependent variables - if the concentrations are rigidly constrained - and 6 reactions which are described in the SI.The homogeneous redox catalysis reactions depicted earlier are introduced through (3). ${ }^{6,36}$

$$
\mathrm{Fe}(\text { phen })_{3}^{2+}+\mathrm{BrO}_{2}^{\cdot}+\mathrm{H}^{+} \rightleftharpoons \mathrm{Fe}(\text { phen })_{3}^{3+}+\mathrm{HBrO}_{2}
$$

Step (3) may be reversible, depending on the oxidizing strength of the BZ reaction catalyst. Typically, it is more reversible and slower for $\mathrm{Ce}^{3+/ 4+}$ or $\mathrm{Ru}(\mathrm{bpy})_{3}{ }^{2+/ 3+}$ systems than for a less oxidizing redox catalyst, such as ferroin, where this step is right-hand shifted and close to diffusion-limited with $k_{f}$ $=10^{9} \mathrm{M}^{-1} \cdot \mathrm{s}^{-1}$ and $k_{b}=33 \mathrm{M}^{-1} \cdot \mathrm{s}^{-1} \cdot{ }^{46}$ Implementation of the Oregonator model was purely qualitative and no attempt has been made to quantitatively match the current amplitude or period with that observed experimentally. The intention was to ob- 
serve the effect - if any - this model would project when coupled with SECM confinement.

Figure 3a illustrates several simulated chronoamperograms obtained from this simulation at different tip-substrate distances for one oscillation. Multiple oscillations were simulated (not shown), and are in good agreement with the experimental observations (Figure 2), in that no change in the frequency is observed. As the tip-substrate distance decreases, the maximum current decreases concomitantly, such that when a plot of the maximum $(\triangle)$ and minimum $(\circ)$ current - normalized versus their requisite signal at $125 \mu \mathrm{m}$ tip-distance - is overlaid against the pure negative feedback curve, they are slightly higher (Figure 3b), which describes diffusion hindrance by the tip-substrate geometry and confinement. The deviation from pure negative feedback is slightly larger for the maximum current than for the minimum one, in qualitative agreement with the experimental observations. The simulated approach curves are also shift towards the substrate, suggesting the intervention of homogeneous redox catalysis reactions (3). Despite similitudes, this model insufficiently explains the whole process occurring experimentally and particularly the amplitude increase when the BZ reaction is confined within $12-15 \mu \mathrm{m}$ from a substrate. Albeit this is a simplified strategy not as sophisticated as reaction-convection-diffusion models presented recently, ${ }^{47}$ it seems however, emblematic of the qualitatively observed reaction. That is, the entire reaction solution changes colour periodically with no spiral wave formation. This means that the oscillation period is smaller than the characteristic diffusion time of water-soluble intermediates, i.e. the confined system can be considered homogenous.

\subsection{SECM Approach Curves in BZ Solution in the Absence of Malonic Acid.}

If the nature of the substrate is negligible, the simulation of the system based on the Oregonator model is also unsatisfactory, thus revealing the intervention of transport (travelling waves) or chemical phenomena. This section investigates the chemical contribution to the observed phenomenon. To do so, the system was chemically simplified by studying it in the absence of malonic acid and, therefore, in the absence of oscillations. In this way, the blue trace plotted in Figure 4a, without current normalization, was recorded with all other BZ reagents maintained.

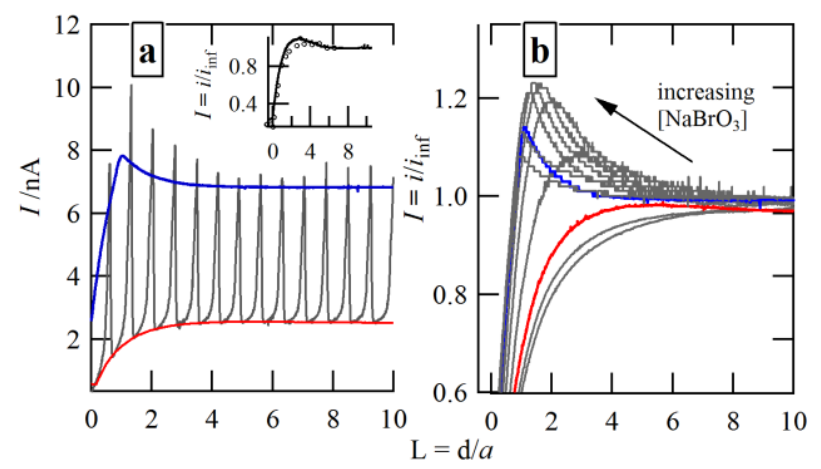

Figure 4.[a] SECM approach curves without current normalization at a glass substrate for a typical BZ solution (-), along with the system without malonic acid, but with $180(-)$ and $5 \mathrm{mM}(-)$ of $\mathrm{NaBrO}_{3}$. Inset, comparison of the current normalized $10 \mathrm{mM}$ $\mathrm{NaBrO}_{3}$ SECM approach curves from [a] (-) and the normalized average minimum oscillation current recorded in transient mode (०). [b] Overlay of probe approach curves in an aqueous solution containing $2 \mathrm{mM}$ ferroin, $1 \mathrm{M} \mathrm{H}_{2} \mathrm{SO}_{4}$, and $\mathrm{NaBrO}_{3}$ varied iteratively from 1 to $504 \mathrm{mM}$.

\subsubsection{Analysis by an Apparent EC' Mechanism.}

When compared to the case of $\mathrm{Fe}\left(\right.$ phen) ${ }_{3}{ }^{3+}$ alone (no bromate, no malonic acid), which is close to the red trace in Figure $4 \mathrm{a}$, a higher current is observed at infinite tip-substrate distance. This indicates the intervention of redox catalysis through reaction (3), suggesting that even in the absence of malonic acid, $\mathrm{BrO}_{3}^{-}$is decomposed in solution into the different brominated oxidants and radicals involved in the BZ scheme. Then, a simplified approach consists of analyzing the electrochemical response in the absence of malonic acid by an apparent $\mathrm{EC}^{\prime}$ mechanism as presented in section 2.1 where equations (1) and (2) are used with Ox, Red, and A for respectively $\mathrm{Fe}$ (phen $)_{3}{ }^{3+}, \mathrm{Fe}$ (phen $)_{3}{ }^{2+}$ and $\mathrm{BrO}_{3}$ such that $k_{\text {homo }}$ is the apparent catalytic rate of the entire process.

Within Figure S3 ( $\square$ ) are graphed the values of the experimental tip current at infinite distance, $i_{\text {inf }}$, while increasing the amount of $\left[\mathrm{NaBrO}_{3}\right]$ added to a $\mathrm{Fe}$ (phen) ${ }_{3}{ }^{2+}$ solution. Bromate, along with its sister oxidative species in solution $\left(\mathrm{Br}_{2}, \mathrm{HOBr}\right.$, and $\mathrm{HBrO}_{2}$ ), are known to directly oxidize ferroin to ferriin. ${ }^{28}$ In this way, when the reaction mixture is prepared, all the ferroin is oxidized to ferriin; this was observed as an almost instantaneous change in colour of the solution, from red to blue, upon addition of $\mathrm{NaBrO}_{3}$ to the acidic ferroin solution. Moreover, reducing $\mathrm{Fe}$ (phen) ${ }_{3}{ }^{3+}$ at the tip initiates theEC ${ }^{\prime}$ scheme. Then an increase in $i_{\text {inf }}$ was observed with increased $\left[\mathrm{NaBrO}_{3}\right]$, in agreement with the intervention of the $\mathrm{C}^{\prime}$ component of an EC' scheme. The catalytic effect plateaus, however, at $180 \mathrm{mM}$ (Figure S3), suggesting several inhibiting processes. Indeed, the amount of $\mathrm{Br}^{-}$, a known inhibitor of the $\mathrm{BZ}$ reaction, ${ }^{14}$ may limit further catalysis through a negative feedback mechanism similar to that present in an oscillating BZ solution with a full complement of reagents. Regardless however, these data provide evidence that the concentration gradient of bromate is playing a role.

From a mechanistic point of view, the evolution of $i_{\text {inf }}$ for different $k_{\text {homo }}$ values was obtained within the simulation, whilst varying $\left[\mathrm{NaBrO}_{3}\right]$, and compared to the experimental values. In Figure S3, two values of $k_{\text {homo }}$ have been exemplified through the overlay of their plots, $a$ and $b$, for an apparent catalytic rate $k_{\text {homo }}$ equal to 100 and $50 \mathrm{M}^{-1} \cdot \mathrm{s}^{-1}$, respectively. Then, $50 \mathrm{M}^{-1} \cdot \mathrm{s}^{-1}$ provides the value for the overall apparent homogeneous catalytic rate with closest fit to the experimental curve. This value agrees with that of the rate determining step reported by Field and Försterling ${ }^{46}$ of $42 \mathrm{M}^{-1} \cdot \mathrm{s}^{-1}$.

As proposed in 2.1, the analysis of the SECM approach curve should also be insightful. To explore the influence and complexity of the brominated species catalytic role further, a series of SECM approach curves were performed towards the glass substrate, in the absence of malonic acid, whilst changing $\left[\mathrm{NaBrO}_{3}\right]$ (Figure 4 b). For $\left[\mathrm{NaBrO}_{3}\right]<5 \mathrm{mM}$ ), the approach curves exhibit negative - or only a small trace of feedback. For $\left(\left[\mathrm{NaBrO}_{3}\right]>5 \mathrm{mM}\right)$, a peak emerges $\left(i_{\text {peak }}\right)$ that increases with increasing concentration until $\left[\mathrm{BrO}_{3}{ }^{-}\right] \approx 100 \mathrm{mM}$. Commensurate with the peak emergence, a shifting in the whole feedback effect closer to the substrate position (low L values) with progressive increases in $\left[\mathrm{NaBrO}_{3}\right]$ was also observed. 
The latter observation is in qualitative agreement with the simulated approach curves presented in Figure 1 and would also reveal the intervention of $\mathrm{EC}^{\prime}$ reactions. However, this simplified $\mathrm{EC}^{\prime}$ model does not replicate the apparent positive feedback observed experimentally. The incorporation of a heterogeneous substrate reaction was also attempted (data not shown); however, since the optimized homogeneous reaction rate was high (based on $i_{\text {inf }}$ ), any heterogeneous rate employed either produced a negative or positive feedback response, in good agreement with SECM theory for coupled homo/heterogeneous reactions. ${ }^{35,36,38,42,48}$

\subsubsection{Reactivity from the Envelope of the Oscil- lations.}

Before scrutinizing deeper the origin of this intricate partial feedback, the approach curves performed in the $180 \mathrm{mM}$ $\mathrm{NaBrO}_{3}$ solution in the absence and presence of malonic acid were compared (Figure 4a).In both cases, the same apparent partial positive feedback is present at roughly the same tipsubstrate distance. Moreover, the current profiles of these two curves are in good agreement in shape and absolute tip current values. The curve recorded in the absence of malonic acid corresponds to the upper envelope of the oscillating curve. Even though there are no oscillations detected at the microelectrode in the absence of malonic acid, the electrochemical response recorded at the tip shows the complexity of the catalytic schemes at play between ferroin and bromate or its related, brominated species.

Figure 4aalso provides a comparison of the approach curves for the $5 \mathrm{mM} \mathrm{NaBrO}$ case without malonic acid against the conventional BZ solution, again without current normalization. This curve corresponds to the lower envelope of the oscillating curve. Similarly, in the inset of Figure 4a, the mean minimum oscillation current recorded at different tip-substrate distances in the transient mode (Figure 2b) can be superimposed in good agreement with the approach curve recorded in the $10 \mathrm{mM} \mathrm{NaBrO}_{3}$ solution without malonic acid.

These observations suggest that under the oscillation regime, when the current is minimal, the local equivalent bromate concentration is between 5 and $10 \mathrm{mM}$ whilst at its maximum oscillation current, it is likewise maximal $\sim 180 \mathrm{mM}$. These experiments confirm the intuitive hypothesis that the oscillation of ferroin in the BZ system is mostly controlled through its catalytic oxidation by the intermediate brominated oxidants in a low and high concentration regime. It also shows that the peculiar apparent positive feedback effect can be understood in terms of the ferroin/bromate catalytic oxidation chemistry. This also rules out, at least in a first approximation, the influence of spatiotemporal phenomena. The approach curves recorded in the absence of malonic acid (or the envelope of the current oscillation with the distance) can then identify these concentration regimes. In turn, these approach curves allow an indirect estimate of the apparent local concentration of the reactive species generated during the $\mathrm{BZ}$ reaction in terms of the equivalent bromate concentration in solution.

Such a strategy is particularly helpful for indirectly assessing the amount of reactive species in $\mathrm{BZ}$ reactions at interfaces (near vessel walls or at soft interfaces: emulsion ${ }^{32,33,49}$ or vesicles $\left.{ }^{31,34,50}\right)$. To illustrate this potentiality further, SECM approach curves were acquired with the BZ solution without malonic acid at a liquid|liquid interface between water (w) and a pure 1,2-dichloroethane (DCE) phase. The w|DCE approach curve overlaps the pure negative feedback curve (Figure S4), suggesting that in the vicinity of the DCE interface, the bromate solution is devoid of reactive intermediates. A likely mechanism is that the hydrophobic and reactive species (e.g. $\mathrm{BrO}_{2}^{\circ}, \mathrm{Br}_{2}$ ) partition and irreversibly react in the organic phase, thus inhibiting their contribution to the catalytic reactions. Therefore, even if a soft interface would behave as an insulating interface in terms of ion and electron transfer, it is likely not inert chemically toward reactive neutral brominated intermediates of the BZ reaction. This should impact the extent of transmission of the $\mathrm{BZ}$ reaction in biphasic systems. $^{14,26,29}$

\subsection{Towards a Full Mechanistic Description}

The partial positive feedback in the SECM approach curve performed in a BZ solution has a redox catalytic chemical origin, even though it is not sufficient to fully explain it. A more detailed chemical model was constructed using the 11 reactions described by Field and Försterling, ${ }^{46,51}$ a complete list of the parameters as well as the reactions can be found in Tables S2 and S3 (SI), respectively. Even if the complete reaction scheme was modelled, it is shown that the major contributions to kinetic control is provided by reactions

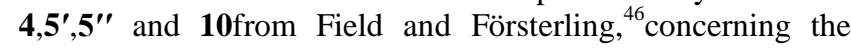
consumption of the intermediate $\mathrm{HBrO}_{2}$ for generation of $\mathrm{BrO}_{2}{ }^{\circ}$ :

$$
\begin{aligned}
& \mathrm{HBrO}_{2}+\mathrm{HBrO}_{2} \underset{k_{-}}{\stackrel{k_{+}}{\rightleftharpoons}} \mathrm{HOBr}+\mathrm{HBrO}_{3}^{-}+\mathrm{H}_{2} \mathrm{O} \\
& \mathrm{HBrO}_{2}+\mathrm{BrO}_{3}^{-}+\mathrm{H}^{+} \underset{k_{-}}{\rightleftharpoons} \mathrm{Br}_{2} \mathrm{O}_{4}+\mathrm{H}_{2} \mathrm{O} \\
& \mathrm{Br}_{2} \mathrm{O}_{4} \underset{1.4 \times 10^{9} \mathrm{M}^{-1} \cdot \mathrm{s}^{-1}}{\rightleftharpoons} 2 \mathrm{BrO}_{2}^{.}
\end{aligned}
$$

whose subsequent reactions are the fastest. It has been recognized that - for the case of $\mathrm{Fe}(\text { phen })_{3}{ }^{2+} / \mathrm{Fe}(\text { phen })_{3}{ }^{3+}-\mathbf{5}^{\prime}$ is rate determining ${ }^{46,51}$ and $\mathrm{BrO}_{2}{ }^{\cdot}$ is the key chemical species regulating the homogeneous catalytic oxidation of ferroin (3).

The latter reaction (3) shows the intervention of an autocatalytic reaction as it regenerates $\mathrm{HBrO}_{2}$ that is involved in $\mathbf{5}^{\prime}$ in addition to the redox catalyst, ferriin. These 4 reactions are then anticipated to explain qualitatively the higher regeneration of ferriin and therefore the apparent positive feedback observed in the approach curves. Indeed based on (3), the catalytic regeneration of $\mathrm{Fe}$ (phen $)_{3}{ }^{3+}$ by brominated species is $k_{\mathrm{f}}\left[\mathrm{Fe}(\text { phen })_{3}{ }^{2+}\right]\left[\mathrm{BrO}_{2}{ }^{\circ}\right]$, which can be roughly approximated from steady-state assumption to $k_{+5^{\prime}}{ }^{2}\left[\mathrm{BrO}_{3}{ }^{-}\right]^{2} / k_{+4}$. It was then logical to focus only on reaction $\mathbf{5}^{\prime}$ and maintain the rates of the other reactions as they have been described previously, thereby, greatly simplifying the simulations.

Similar to the one-step reaction mechanism, $i_{\text {inf }}$ was recorded for the complex simulation at varied concentrations of $\mathrm{NaBrO}_{3}$ and two curves, for $k_{+, 5^{\prime}}$ equal to 100 and $50 \mathrm{M}^{-1} \cdot \mathrm{s}^{-1}$, have been plotted in Figure S3 as curves c and d, respectively. These curves demonstrate a fair agreement with the experimental evolution. This indicates that - similar to the simplified one-step catalytic simulation - the 11-reaction, more complex system is governed by a reaction with a rate determining step, likely $\mathbf{5}^{\prime}$, with a value of $\sim 50-100 \mathrm{M}^{-1} \cdot \mathrm{s}^{-1}$, in very good agreement with the value proposed by Field and Försterling. ${ }^{46}$ 


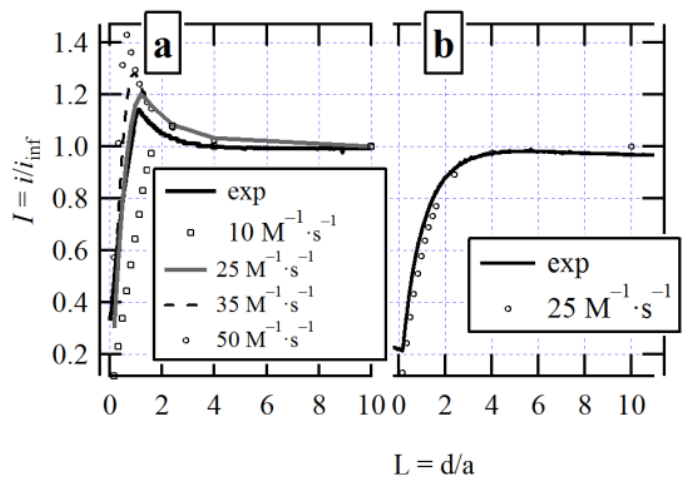

Figure 5: SECM probe approach curves using the 11 homogeneous reaction set [a] where the rate, $k_{+}$, of $\mathbf{5}^{\prime}$ was varied as indicated with $180 \mathrm{mM} \mathrm{NaBrO}$; overlaid (-) is the experimental approach curve at $180 \mathrm{mM} \mathrm{NaBrO}_{3}$. [b] the same simulation as [a], however, with $\left[\mathrm{BrO}_{3}{ }^{-}\right]=5 \mathrm{mM}$ overlaid with its requisite experimental curve.

Figure 5a illustrates the probe approach curves obtained using this simulation while varying the forward rate constant, $k_{+, 5^{\prime}}$. Simulated SECM approach curves were then generated using this more complete system and are plotted in Figure 5a and $b$ for a solution with 180 and $5 \mathrm{mM}$ of $\mathrm{NaBrO}_{3}$, respectively; experimental curves ( - ) have been overlaid for comparison. The first remarkable result is that the complete mechanism reproduces the appearance of a peak in the approach curve, both in shape and position, resulting from the enhancement of the catalytic route under given confinement. It confirms that this peak may not be due to spatiotemporal phenomena, but is ruled by chemical processes of characteristic length provided by the SECM confinement. Moreover, the faster the main reaction, $k_{+, 5}$, the higher the catalytic enhancement and the higher the peak. In the case of Figure S3a, the approach curve when $k_{+, 5^{\prime}}$ was set equal to $25 \mathrm{M}^{-1} \cdot \mathrm{s}^{-1}$ is in good agreement with the experimental trace in its normalized form, while larger $k_{+, 5^{\prime}}$ values demonstrated poorer overlap owing to generating a higher peak in the approach curve. Finally, the rate constant value obtained in this configuration $\left(k_{+, 5^{\prime}}=25 \mathrm{M}^{-1} \cdot \mathrm{s}^{-1}\right)$ is reasonable compared to the one obtained for a one-step homogeneous reaction $\left(50<k<100 \mathrm{M}^{-1} \cdot \mathrm{s}^{-1}\right)$ considering the complexity of the system and the fact that only one reaction relative to the production of $\mathrm{BrO}_{2}{ }^{\circ}$ is changed in the model. Finally, the peculiarity observed here is due to the detection by the SECM tip of the reaction of the $\mathrm{BrO}_{2}{ }^{\circ}$ reactive species whose concentration, in the vicinity of the electrode surface positioned at 125 and $2 \mu \mathrm{m}$ tip-substrate distances, was determined to be 9.1 and $3.6 \mu \mathrm{mol} \cdot \mathrm{L}^{-1}$, respectively, whilst $\sim 90 \mu \mathrm{mol} \cdot \mathrm{L}^{-1}$ in the bulk.

\section{CONCLUSIONS}

A simple strategy for testing an $\mathrm{EC}^{\prime}$ mechanism using SECM approach curves versus an insulating substrate has been proposed and validated by employing the BZ reaction as a model system. An $\mathrm{EC}^{\prime}$ theoretical model, along with a more complex 11-reaction simulation have been used to explain an unexpected increase in the current amplitude of the BZ oscillation at small tip-substrate distances $(\mathrm{L} \approx 1)$ across various insulating substrates. The Oregonator model, traditionally used to describe the BZ system, was insufficient to simulate quanti- tatively the amplitude and the period of the oscillation as well as the feedback observed experimentally. However, the EC' and 11-reaction homogeneous redox catalysis schemes were able to describe the mechanism in terms of the local $\mathrm{BrO}_{3}$ concentration through comparison to experimental approach curves recorded in the absence of malonic acid. This suggests that the apparent partial positive feedback can be explained by a simple application of the catalytic reactions themselves without a need to consider more complex bifurcation models; i.e. that it is owing to chemical wave propagation (direct changes in the concentration gradient of key bromate species).

These findings have implications towards inter-vesicular chemical coupling and indicate an optimal distance for vesicle spacing or size for enhanced reaction kinetics. Additionally, they suggest the potentiality of SECM to characterize homogeneous redox catalysis reactions, and indirectly depict the stability of short-lived intermediate reactive species (herein the $\mathrm{BrO}_{2}{ }^{\circ}$ radical is indirectly monitored). While the $\mathrm{BZ}$ reaction is exemplified here, this approach can easily be extended to other fields: e.g. ECL, ${ }^{11-13}$ cross-coupling reactions(as those involved in click-chemistry), ${ }^{8,9}$ organometallic redox processes, ${ }^{10}$ and proton coupled electron transfer reactions involved in many energy-related fields. $5,6,52,53$

\section{ASSOCIATED CONTENT}

Supplementary Information: Experimental details; Figure $\mathrm{S} 1$ : Simulated values of $I=i_{\text {min }} / i_{\text {inf }}$ (a) and $i_{\text {inf }}$ (b) versus $k_{\text {homo- }}$ for EC'; Figure S2: Oscillation amplitude versus tip-substrate distance for different substrates; Oregonator Equations; Figure S3: Plots of $i_{\text {inf }}$ vs. $\left[\mathrm{NaBrO}_{3}\right]$, experiments and simulation; Figure S4: Approach curve towards a w|DCE interface; Figure S5: CV in a BZ solution; Table S1: Water contact angle measurements; Table S2: COMSOL parameters for the Field and Försterling model; Table S3: 11 reactions with associated rate constants and rate equations employed in the COMSOL model.

\section{AUTHOR INFORMATION}

\section{Corresponding Author}

${ }^{\dagger}$ E-mail address: frederic.kanoufi@ univ-paris-diderot.fr;

\section{Notes}

The authors declare no competing financial interest

\section{ACKNOWLEDGEMENTS}

The authors would like to acknowledge support from CNRS and Labex MICHEM.

\section{RERFERENCES}

(1) Andrieux, C.P.; Dumas-Bouchiat, J.M.; Saveant, J.M. J. Electroanal. Chem. Interfacial Electrochem.1978, 87, 39-53.

(2) Savéant, J.M. Chem. Rev. 2008, 108, 2348-2378.

(3) Cannan, S.; Cervera, J.; Steliaros, R.J.; Bitziou, E.; Whitworth, A.L.; Unwin, P.R. Phys. Chem. Chem. Phys. 2011, 13, 5403-5412.

(4) Calhoun, R.L.; Bard, A.J. J. Electrochem. Soc.2012, 159, F42F47.

(5) Lin, Q.; Li, Q.; Batchelor-McAuley, C.; Compton, R.G. J. Phys. Chem. C2014, 119, 1489-1495.

(6) Costentin, C.; Drouet, S.; Robert, M.; Savéant, J.M. Science 2012, 338, 90-94.

(7) Léger, C.; Bertrand, P. Chem. Rev. 2008, 108, 2379-2438.

(8) Liang, C.K.; Dubacheva, G.V.; Buffeteau, T.; Cavagnat, D.; Hapiot, P.; Fabre, B.; Tucker, J.H.R.; Bassani, D.M. Chem. Eur. J.2013, 19, 12748-12758. 
(9) Zhao, L.; Zhao, F.; Zeng, B. Biosens. Bioelectron.2014, 62, 19 24.

(10) Magenau, A.J.D.; Strandwitz, N.C.; Gennaro, A.; Matyjaszewski, K. Science2011, 332, 81-84. 57.

(11) Bard, A.J.; Ding, Z.; Myung, N. Struct. Bonding 2005, 118, 1-

(12) Dick, J. E.; Renault, C.; Kim, B.-K.; Bard, A.J. J. Am. Chem. Soc.2014, 136, 13546-13549.

(13) Swanick, K.N.; Hesari, M.; Workentin, M.S.; Ding, Z. J. Am. Chem. Soc.2012, 134, 15205-15208.

(14) Epstein, I.R. Chem. Commun.2014, 50, 10758-10767.

(15) Corbel, J.M. L.; van Lingen, J.N. J.; Zevenbergen, J.F.; Gijzeman, O.L.J.; Meijerink, A. Angew. Chem. Int. Ed.2013, 52, 290303.

(16) Ueki, T.; Yoshida, R. Phys. Chem. Chem. Phys.2014, 16, 10388-10397.

(17) Yuan, C.; Guo, J.; Tan, M.; Guo, M.; Qiu, L.; Yan, F. ACS Macro Letters 2014, 3, 271-275.

(18) Arimura, T.; Mukai, M. Chem. Commun.2014, 50, 5861-5863.

(19) Hara, Y.; Mayama, H.; Fujimoto, K. J. Phys. Chem. B2014, $118,6931-6936$.

(20) Lu, X.; Ren, L.; Gao, Q.; Zhao, Y.; Wang, S.; Yang, J.; Epstein, I. R. Chem. Commun.2013, 49, 7690-7692.

(21) Zhang, Y.; Zhou, N.; Akella, S.; Kuang, Y.; Kim, D.; Schwartz, A.; Bezpalko, M.; Foxman, B. M.; Fraden, S.; Epstein, I. R.; Xu, B. Angew. Chem. Int. Ed.2013, 52, 11494-11498.

(22) Field, R.J.; Koros, E.; Noyes, R.M. J. Am. Chem. Soc.1972, $94,8649-8664$

(23) Bell, J.G.; Green, J.R.; Wang, J. J. Phys. Chem. A2014, 118 , 9795-9800.

(24) Amemiya, T.; Nakaiwa, M.; Ohmori, T.; Yamaguchi, T. Phys. D1995, 84, 103-111.

(25) Zhang, Y.; Zhou, R.; Shi, J.; Zhou, N.; Epstein, I.R.; Xu, B. J. Phys. Chem. B2013, 117, 6566-6573.

(26) Tomasi, R.; Noel, J.-M.; Zenati, A.; Ristori, S.; Rossi, F.; Cabuil, V.; Kanoufi, F.; Abou-Hassan, A. Chem. Sci.2014, 5, 18541859.

(27) Rossi, F.; Budroni, M.A.; Marchettini, N.; Cutietta, L.; Rustici, M.; Liveri, M.L.T. Chem. Phys. Lett.2009, 480, 322-326.

(28) Keki, S.; Magyar, I.; Beck, M.T.; Gaspar, V. J. Phys. Chem.1992, 96, 1725-1729.

(29) Tompkins, N.; Li, N.; Girabawe, C.; Heymann, M.; Ermentrout, G.B.; Epstein, I.R.; Fraden, S. Proc. Natl. Acad. Sci. U. S. A.2014, 111, 4397-4402.

(30) Turing, A. M. Trans. Roy. Soc. 1952, B237, 37-72.

(31) Tan, Y.-C.; Hettiarachchi, K.; Siu, M.; Pan, Y.-R.; Lee, A.P. J. Am. Chem. Soc.2006, 128, 5656-5658.

(32) Delgado, J.; Li, N.; Leda, M.; Gonzalez-Ochoa, H.O.; Fraden, S.; Epstein, I.R. Soft Matter2011, 7, 3155-3167.

(33) Joensson, H.N.; Andersson Svahn, H. Angew. Chem. Int. Ed.2012, 51, 12176-12192.

(34) Seth, A.; Béalle, G.; Santanach-Carreras, E.; Abou-Hassan, A.; Ménager, C. Adv. Mater.2012, 24, 3544-3548.

(35) Demaille, C.; Unwin, P.R.; Bard, A.J. J. Phys. Chem.1996, 100, 14137-14143.

(36) Kanoufi, F.; Cannes, C.; Zu, Y.; Bard, A.J. J. Phys. Chem. B 2001, 105, 8951-8962.

(37) Bi, S.; Liu, B.; Fan, F.-R.F.; Bard, A.J. J. Am. Chem. Soc.2005, 127, 3690-3691.

(38) Amemiya, S.; Bard, A.J.; Fan, F.R.F.; Mirkin, M.V.; Unwin, P.R. Annu. Rev. Anal. Chem.2008, 1, 95-131.

(39) Ktari, N.; Combellas, C.; Kanoufi, F. J. Phys. Chem. C2011, 115, 17891-17897.

(40) Noël, J.-M.; Latus, A.; Lagrost, C.; Volanschi, E.; Hapiot, P. J. Am. Chem. Soc.2012, 134, 2835-2841.

(41) Zhang, M.M.N.; Long, Y.-T.; Ding, Z. J. Inorg. Biochem.2012, 108, 115-122.
(42) Ekanayake, C.B.; Wijesinghe, M.B.; Zoski, C.G. Anal. Chem.2013, 85, 4022-4029.

(43) Cao, F.; Kim, J.; Bard, A.J. J. Am. Chem. Soc.2014, 136, 18163-18169.

(44) Stockmann, T.J.; Zhang, J.; Montgomery, A.-M.; Ding, Z. Anal. Chim. Acta 2014, 821, 41-47.

(45) Field, R.J.; Noyes, R.M. J. Chem. Phys.1974, 60, 1877-1884.

(46) Field, R.J.; Försterling, H.D. J. Phys. Chem.1986, 90, 54005407.

(47) Rossi, F.; Budroni, M.A.; Marchettini, N.; CarballidoLandeira, J. Chaos 2012, 22, 037109-037101-037109-037111.

(48) Nunige, S.; Cornut, R.; Hazimeh, H.; Hauquier, F.; Lefrou, C.; Combellas, C.; Kanoufi, F. Angew. Chem. Int. Ed.2012, 51, 52085212 .

(49) Thutupalli, S.; Herminghaus, S.; Seemann, R. Soft Matter2011, 7, 1312-1320.

(50) Luo, T.; Srivastava, V.; Ren, Y.; Robinson, D.N. Appl. Phys. Lett.2014, 104, -

(51) Yan, S. Naturwissenschaften, Philipps-Universität Marburg, 2001.

(52) Bian, X.; Scanlon, M. D.; Wang, S.; Liao, L.; Tang, Y.; Liu, B.; Girault, H.H. Chem. Sci.2013, 4, 3432-3441.

(53) Scanlon, M.D. ChemCatChem 2013, 5, 1696-1697. 